\title{
Mechanical Characterization of Hardness and Surface Roughness for Cryo Treated 7075 Aluminium Alloy
}

\author{
D. Khedekar ${ }^{1 *}$, S.Patil $^{2}$, C. Gogte ${ }^{3}$ \\ ${ }^{1}$ Associate Professor, Jawaharlal Nehru Engineering College, Aurangabad, India \\ ${ }^{2}$ Associate Professor, ${ }^{3}$ Professor, Marathwada Institute of Technology, Aurangabad, India \\ \{dskhedekar2016@gmail.com\}
}

\begin{abstract}
Aluminium and its alloys provide the solution in many applications as it is light in weight, strong and is highly and easily recyclable. Good part is large amount of material is available for recycling that is easily recycled by just $5 \%$ energy required to produce, without deteriorating the properties so reducing the cost. Aluminium is increasingly the ?material of choice? because of strength and environmental advantages. The future is having lot of scope of increasing application, as there is lot of varieties of aluminium alloys. AA 7075 material has very critical applications so more emphasis is on increasing the durability of materials by carrying out proper treatment cycle. In this research work along with the convectional heat treatment cryogenic treatment is carried out. The method, sequence and the parameters of treatment are set. The 7075 aluminium alloy is widely used in many mechanical applications where mostly failure occurs due to wear. In order to improve wear, hardness and surface roughness plays important role. Different heat treatment, cryogenic cycle and their sequence of treatment are studied for yielding better hardness and surface finish increasing the life. This work is carried with basic T6 treatment and intermediate cryogenic treatment at different process parameters showing the changes in hardness and surface roughness, finding the proper cycle and parameters of treatments improving the properties.
\end{abstract}

Keywords:Artificial Aging, Age Hardenable, Cryogenics, Solutionizing

\section{Introduction}

Aluminium is most abundant metal in earth crust and is second largest used metal and largest nonferrous industry in world. This material use should be increased to maximum in as many numbers of applications as possible, so its properties need to be still improved by providing proper treatments. The major failure of aluminium mechanical components is due to wear so more emphasis is to reduce wear failure. The factors affecting wear are hardness and surface roughness. Work is done to improve its properties by researchers. The effect of cryogenic processing on surface roughness of age hardenable AA6061 alloy is studied showing improvement in surface roughness of this alloy having a good surface finish after machining [1]. Investigators at Marshall Space Flight Center (MSFC) studied the potential benefits of cryogenic treatment for aerospace aluminium alloys reporting the effects of cryogenic treatment on residual stress, tensile strength, hardness, fatigue life, and stress corrosion cracking resistance [2]. The optimization of the cryogenic processing $\mathrm{Al}-\mathrm{Cu}$ alloys is studied [3]. The effects of cryogenic treatment on bearings, gears and engine components to reduce wear and improve performance to optimize lubrication is studied, resulting in the maximum performance of lubricated components, and can significantly extend component life[4]. The effect of cryogenic treatments on 7075 aluminium alloy is studied showing; the effect of cryogenic thermal treatment on the room temperature strength, hardness, and toughness of aluminium 7075-T651, study is done to much extreme conditions of treatment at 2 and $48 \mathrm{hr}$. of cryogenic treatment. The data show that there was no statistically significant effect on basic properties as a result of a 2 -hr. cryogenic treatment. There was a slight increase in strength and toughness and a slight decrease in hardness as a result of $48 \mathrm{hr}$. of cryogenic treatment [5]. No explanation as to how cryogenic treatments could affect the properties of the alloy is provided also no intermediate conditions were considered. In the present work experimentation is carried out at different process parameters for basic T6 treatment and intermediate cryogenics between solutionizing and ageing treatment. The changes in this sample treated material for hardness and surface roughness is checked. Among different experiments done at different soaking time for both the cases, best result giving process is found, that is more increasing the hardness and decreasing the surface roughness emphasising the significance of cryogenic treatment.

B. Iyer, S. Nalbalwar and R. Pawade (Eds.)

ICCASP/ICMMD-2016. Advances in Intelligent Systems Research.

Vol. 137, Pp. 160-164.

(C) 2017. The authors - Published by Atlantis Press

This is an open access article under the CC BY-NC license (http://creativecommons.org/licens)es/by-nc/4.0/). 


\section{Material and Experimentation}

\subsection{Material}

The material 7075 aluminium alloys is high strength low density of $2.8 \mathrm{~g} / \mathrm{cm}^{3}$ material. It is used for number of applications in aircraft, automotive, marine, sports equipment?s, piping systems, high pressure hydraulic units, mechanical components etc. This aluminium alloys is age hardenable, wrought and heat treatable alloy having zinc in maximum proportion and other elements are magnesium, copper, chromium as hardener and very less amount of iron, silicon, manganese and titanium with balance aluminium. The samples of the 7075 aluminium alloys were prepared by wire cutting in the size of $18 \times 16 \times 14 \mathrm{~mm}$ as shown in fig. 1.

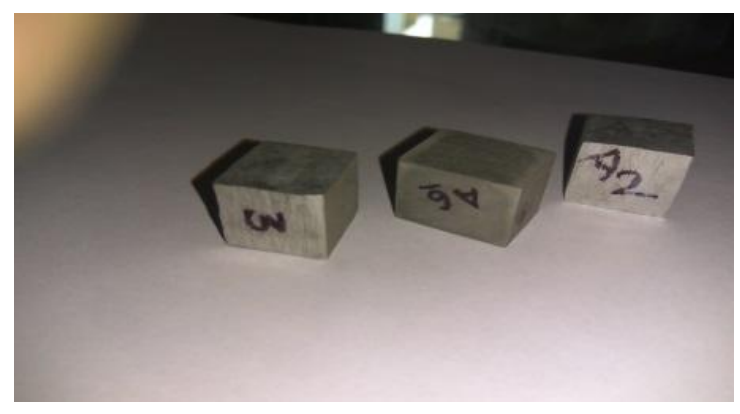

Fig. 1. Samples

\subsection{Method}

Two type of treatments are carried out, basic T6 treatment and intermediate cryogenic treatment in T6. Cryogenic is permanent treatment affecting the entire section or bulk of the component. The effect of cryogenic treatment with convectional heat treatment is studied for changes in hardness and surface roughness affecting the wear resistance property of material.

\section{A. T6 Treatment}

The earlier applications of AA 7075 in aeronautics and almost all the mechanical applications uses the alloy in the T6 condition, which is characterized by the highest ultimate and yield strengths [6]. T6 is carried out in two steps one solutionizing and second aging as shown in fig. 2 . In solutionizing material is heated to $465^{\circ} \mathrm{C}$ soaked at this temperature for 1, 2 and $3 \mathrm{hrs}$. Where in the alloying constituents are forming solid solutions and rapid quenching in water retain the constituents in a supersaturated solid solution. Then aging is carried out in which sample is heated to $120^{\circ} \mathrm{C}$ soaked for $20 \mathrm{hrs}$ and cooled in air. Ageing to room temperature allows for a controlled precipitation of the constituents thereby achieving increased hardness and strength [7].

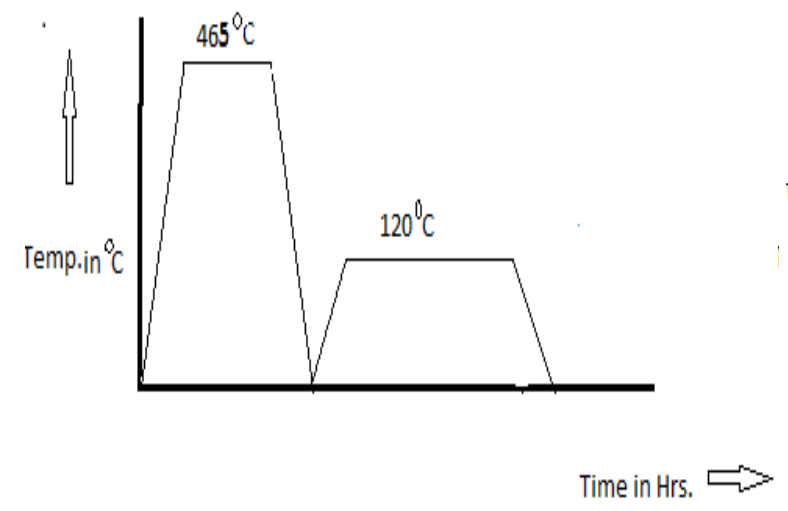

Fig. 2. T6 Treatment

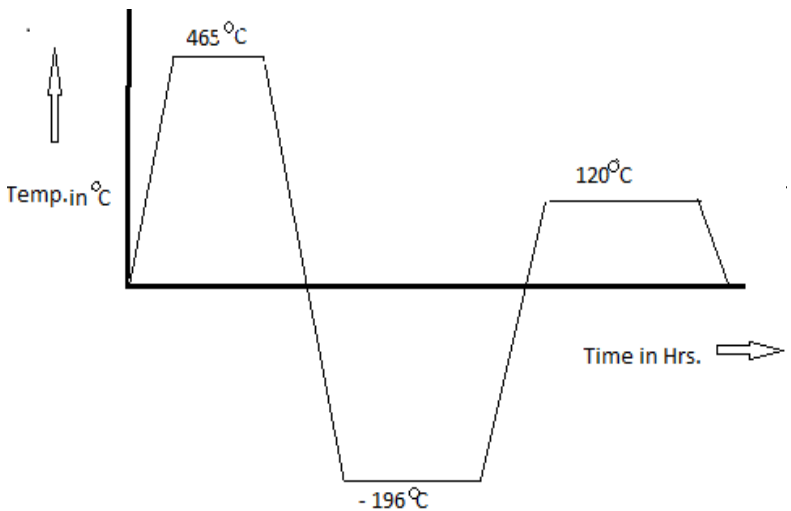

Fig. 3. Solutionizing + Cry. Treatment + Aging 


\section{B. Cryogenic Treatment}

Cryogenic is low temperature treatment below $123 \mathrm{~K}$. The cryogenic process affects both the mechanical and metallurgical properties. Within T6 treatment intermediate cryogenic process is carried by dipping samples in liquid nitrogen tank at $-196^{\circ} \mathrm{C}$ for 12 hrs. as shown in fig. 3.

\subsection{Measurements}

After the experimentation the components were checked for the changes in hardness and surface roughness of the material which affect the wear most.

\section{A. Hardness}

Hardness is measured by using a standard Brinell hardness testing machine, accordance with ASTM E10 standards. Three readings were taken of each specimen before and after treatment at different locations and the average value were considered for more accuracy.

\section{B. Surface Roughness}

The surface roughness was measured by roughness tester stylus probe type Mitutoyu Surf test SJ201P.Checking before and after treatment at three different location and average value was considered.

\section{Results and Discussion}

Treatments were carried out on three samples for each soaking period. Average of three readings per sample of three samples for hardness and surface roughness were measurement before and after the treatment to study percent changes as shown in table 1,2 and fig. 4, 5, 6 and 7 respectively.

Table 1 T6-Treatment

\begin{tabular}{|c|c|c|c|c|c|c|c|c|}
\hline \multirow{2}{*}{ Sr. } & \multicolumn{2}{|c|}{ Soaking (Hrs.) } & \multicolumn{3}{c|}{ Hardness (BHN) } & \multicolumn{2}{c|}{ Surface Roughness (Ra) } \\
\cline { 2 - 9 } No. & Solutionizing & Aging & Before & After & $\begin{array}{c}\% \\
\text { Change }\end{array}$ & Before & After & $\begin{array}{c}\% \\
\text { Change }\end{array}$ \\
\hline 1 & 1 & 20 & 80.3 & 80 & -0.37 & 2.08 & 1.47 & -29 \\
\hline 2 & 2 & 20 & 84 & 79.6 & -5.2 & 1.75 & 0.67 & -61 \\
\hline 3 & 3 & 20 & 84 & 81.3 & -3.2 & 0.84 & 0.75 & -10.7 \\
\hline
\end{tabular}

Table 2 S.T + C.T + Aging Treatment

\begin{tabular}{|c|c|c|c|c|c|c|c|c|c|}
\hline \multirow{2}{*}{$\begin{array}{c}\text { Sr. } \\
\text { No. }\end{array}$} & \multicolumn{3}{|c|}{ Soaking (Hrs.) } & \multicolumn{3}{c|}{ Hardness (BHN) } & \multicolumn{2}{c|}{ Surface Roughness (Ra) } \\
\cline { 2 - 10 } & Solutionizing & $\begin{array}{c}\text { Cryo. } \\
\text { Treat. }\end{array}$ & Aging & Before & After & $\begin{array}{c}\% \\
\text { Change }\end{array}$ & Before & After & $\begin{array}{c}\% \\
\text { Change }\end{array}$ \\
\hline 1 & 1 & 12 & 20 & 80.3 & 84.6 & 5.3 & 1.85 & 0.75 & -59.45 \\
\hline 2 & 2 & 12 & 20 & 80 & 83.3 & 4.1 & 1.54 & 0.74 & -51.9 \\
\hline 3 & 3 & 12 & 20 & 84 & 85 & 1.2 & 1.97 & 1.4 & -28.9 \\
\hline
\end{tabular}




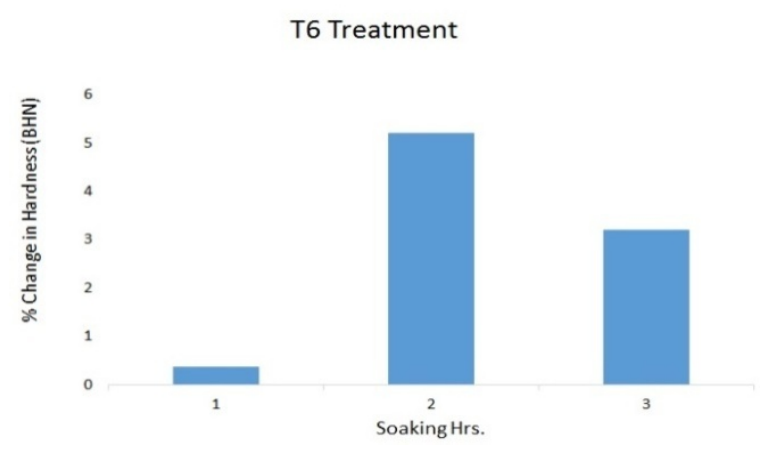

Fig. 4. T6-Effect on Hardness

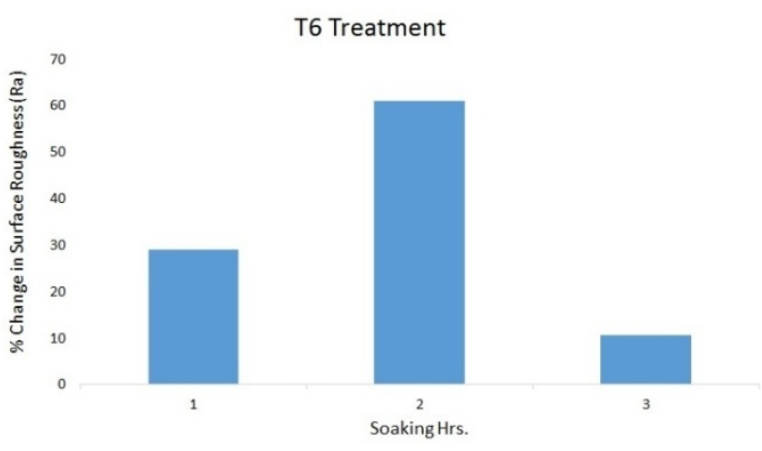

Fig. 5. T6-Effect on Surface Roughness

For the basic T6 treatment as shown in table 1 and fig. 4, 5 it is found that there is decrease in the hardness of samples for all three experiments and for $2 \mathrm{hrs}$ of soaking decrease in hardness is maximum. If we see the trend the change in hardness is increasing and then decreasing with increasing soaking time. The maximum decrease in hardness is observed for $2 \mathrm{hrs}$ of soaking period. Similar trend is observed for surface roughness, for $2 \mathrm{hrs}$ of soaking the surface roughness decrease is maximum giving good surface finish, indicating that $2 \mathrm{hrs}$ is sufficient for complete solutionizing of the content in material leading to super saturated solid solution of this content. Ageing decomposes the super saturated solid solution to finely dispersed precipitate initially less so less decrease in hardness. The fine precipitate increases with time so for $2 \mathrm{hrs}$ soaking hardness decrease is maximum but with still increase in time coursing of precipitate starts to take place decreasing reduction in the hardness. For fine precipitate of $2 \mathrm{hrs}$ surface roughness reduction is also maximum giving good surface finish.

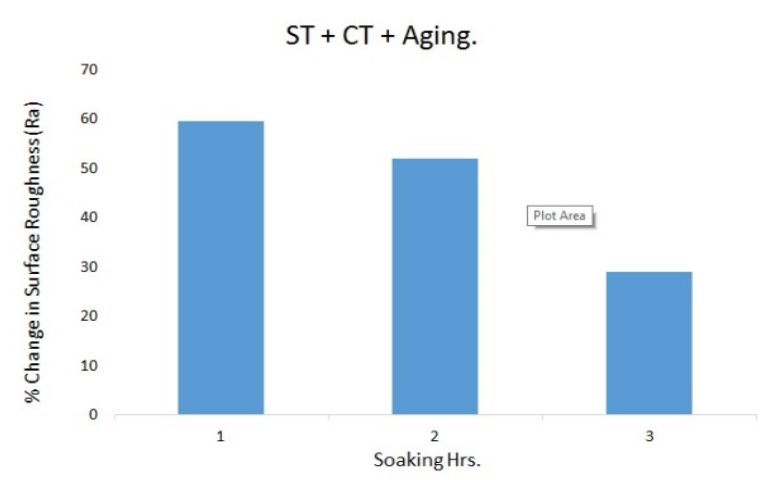

Fig. 6. $\mathrm{ST}+\mathrm{CT}+$ Ageing-Effect on Surface Roughness

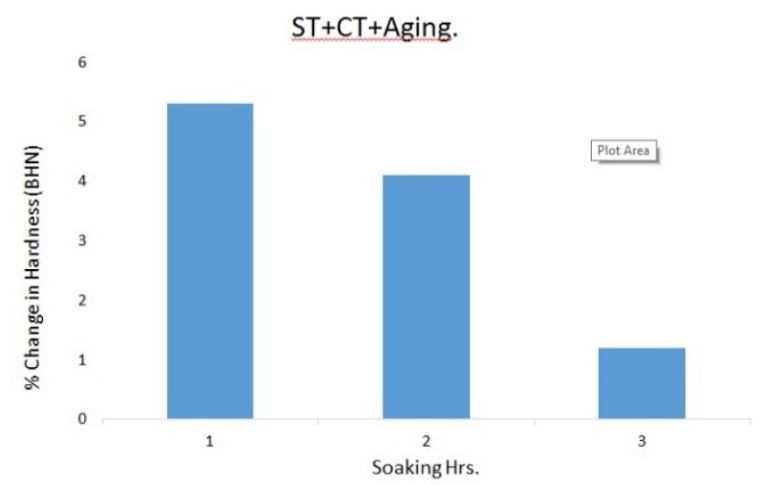

Fig. 7. ST+CT+Ageing-Effect on Hardness

From the result as shown in table 2 and fig. 6, 7 of intermediate cryogenic treatment it is found that there is increase in hardness of the material because of process. The percent increase of hardness is more for $1 \mathrm{hr}$. soaking of solutionizing and the rate of increasing the hardness decreases with increase in the soaking hours. There is decrease in surface roughness with intermediate cryogenic treatment. The trend observed for surface roughness is similar to the hardness; the rate of surface roughness decrease with soaking period. From the result it is found that for intermediate cryogenic treatment the percent increase in the hardness is more with solutionizing for $1 \mathrm{hr}$ soaking and the percent rate decreases with increase in soaking period. Similarly percentage decrease in surface roughness is more for $1 \mathrm{hr}$ soaking and the rate decreases with increasing the soaking period slightly increasing the surface distortion increasing the roughness. The samples subjected to $196^{\circ} \mathrm{C}$ temperature during cryogenic treatment contracts the aluminum matrix which reduces void, internal defects and lattices parameters increasing volume fraction resulting in increased strength and finish. 


\section{Conclusions}

From the experimental results following conclusions are drawn

- There is decrease in the hardness of material by basic T6 treatment.

- The hardness of material increases with intermediate cryogenic treatment.

- Both the types of process reduce the surface roughness.

- For basic T6 treatment we get better results of hardness and surface roughness for 2 hrs of soaking during solutionizing.

- For intermediate cryogenic treatment we get better results for hardness and surface roughness for $1 \mathrm{hr}$ of soaking during solutionizing.

- Cryogenic treated shows better properties than just basic T6 treatment.

- Cryogenic treatment carried is of help as it improves the hardness and reduces surface roughness.

\section{References}

[1]. C. L. Gogte, Ajay Likhite, Dilip Peshwe, Aniruddha Bhokarikar, Rahul Shetty, "Effect of cryogenic Processing on Surface Roughness of Age HardenableAA6061 Alloy", Materials and Manufacturing Processes, 29: 710日714, 2014.

[2]. Po Chen, Tina Malone, Pablo Torres, ]Effects Of Cryogenic Treatment On The Residual Stress And Mechanical Properties Of An Aerospace Aluminum Alloy", $5^{\text {th }}$ Conference on Aerospace Material, Processes and Environmental Technology, 2002.

[3]. Stankowiak, A. W. Bydałek, "The Optimization of the Cryogenic Processing Al-Cu Alloys", Archives Of Foundry Engineering Volume 7, Issue 3/2007, 141-146.

[4]. Richard N .Wurzbach, William DeFelice, "Improving component wear performance through cryogenic treatment", Maintenance Reliability Group Brogue, Pennsylvania.

[5]. K. E. Luley ${ }^{1}$, K .Khan ${ }^{2}$, D. Chaaya ${ }^{3}$, ?The Effect of Cryogenic Treatment on 7075 Aluminum Alloy", Engineering Journal of Materials Engineering and Performance, Volume 11(5) October 2002.

[6]. G. Silva ${ }^{1}$, B. Rivolta ${ }^{2}$, R. Gerosa ${ }^{3}$, U. Derudi ${ }^{3}$, बS Study of the SCC Behaviour of 7075 Aluminum Alloy After One-Step Aging at $163^{\circ} \mathrm{C}$, Journal of Materials Engineering and Performance, $25^{\text {th }}$ April 2012.

[7]. Girisha.H.N ${ }^{1}$, K.V.Sharma ${ }^{2}$, "Influence of Process Parameters on the Mechanical Properties Of Heat Treated Aluminium Copper Magnesium Alloy? International Journal of Innovative Research in Science, Engineering and Technology, Vol. 2, Issue 1, January 2013.

[8]. Nasser Afify ${ }^{1}$, Abdel-Fattah Gaber ${ }^{2}$, Ghada Abbady ${ }^{3}$, "Fine Scale Precipitates in Al-Mg-Zn Alloys after Various Aging Temperatures回, Materials Sciences and Applications, 2011, 2, 427-434.

[9]. Evren $\mathrm{Tan}^{1}$, A D Ogel ${ }^{2}$, ]Influence o f Heat Treatment on the Mechanical Properties of AA 6066 Alloy”, Turkish J . Eng. Env. Sci .31 (2007), 53 回 60.

[10]. D.D. Risanti ${ }^{1}$, M. Yin b ${ }^{2}$, P.E.J.Rivera Díazdel Castillo ${ }^{3}$, S. Vander Zwaag, "A systematic study of the effect of interrupted ageing conditions on the strength and toughness development of AA6061", Materials Science and Engineering A 523 (2009) 990111.

[11]. P. Baldissera ${ }^{1}$, C. Delprete ${ }^{2}$, aDeep Cryogenic Treatment: A Bibliographic Review", The Open Mechanical Engineering Journal, 2008, 2, 1-11.

[12]. Li Jin-feng ${ }^{1}$, PengZhuo-wei ${ }^{2}$, LI Chao-xing ${ }^{3}$, JiaZhi-qiang ${ }^{4}, C h e n$ Wen-jing $^{5}$, ZhengZi-qiao, ${ }^{6}$ ] Mechanical properties, corrosion behaviours and microstructures of 7075 aluminum alloy with various aging treatments", Trans. Nonferrous Met. Soc.China 18(2008)755-765.

[13]. Pavan.K.M ${ }^{1}$, Sachin.L.S ${ }^{2}$, Mayur.S ${ }^{3}$, Chandrashekar ${ }^{3}$. A,B.S. Ajaykumar ${ }^{4}$, Effect Of Cryogenic Treatment On The Mechanical And Microstructural Properties Of Aluminium Alloys-A Brief Study", International Journal of Mechanical And Production Engineering, ISSN: 2320-2092, Volume- 2, Issue5, May-2014.

[14]. Jasim M. Salman ${ }^{1}$, Shaymaa Abbas AbdAlsada ${ }^{2}$, Khadim F. Al-Sultani ${ }^{3}$, IImprovement Properties of 7075-T6 Aluminum Alloy by Quenching in 30\% Polyethylene Glycol and Addition 0.1\%B", Research Journal of Material Sciences, Vol. 1(6), 12-17, July (2013),Pg no.12-17. 